\title{
Investigation of organic foulants behavior on hollow-fiber UF membranes in a drinking water treatment plant
}

\author{
Ping Xiao ${ }^{a}$, Feng Xiao ${ }^{a, *}$, Dong-sheng Wang ${ }^{\mathrm{a}, *}$, Tong Qin ${ }^{\mathrm{b}}$, Shou-ping He ${ }^{\mathrm{b}}$ \\ a State Key Laboratory of Environmental Aquatic Chemistry, Research Center for Eco-Environmental Sciences, Chinese Academy of Sciences, 18, Shuangqing Road, \\ Beijing 100085, China \\ b Water Supply Plant Works of Nantong, Nantong 226007, China
}

\section{A R T I C L E I N F O}

\section{Article history:}

Received 2 March 2012

Received in revised form 22 April 2012

Accepted 23 April 2012

Available online 1 May 2012

\section{Keywords:}

Ultrafiltration (UF) membrane filtration

Organic foulants

Natural organic matter

Accumulation behavior

\begin{abstract}
A B S T R A C T
In the present work, a ultrafiltration (UF) low pressure membrane (LPM) made of polyvinyl chloride (PVC) was used with an inline poly-ferric sulfate coagulation in a full scale drinking water treatment plant. The organic foulants and their accumulation behavior in the membrane filtration were investigated during a whole year operation. The evolutions of the surface morphology of the membranes were characterized by scanning electronic microscopy (SEM) and atomic force microscopy (AFM). The results revealed that the cake layer and pore blocked were responsible for the flux declining. Moreover, the roughness of the surface of the membranes continuously increased with the filtration. In order to identify the constitutes of organic foulants, attenuated total reflectance-fourier transform infrared spectroscopy (ATR-FTIR), high pressure size exclusion chromatography (HPSEC) and fluorescence excitation-emission matrix (EEM) spectrometry were used to examine the desorbed organic matters from the fouled membranes. The results showed that humic substances kept a very stable situation, indicating that it would not be important in the formation of the combined organic fouling layer. Protein/protein-like substances and soluble microbial product-like (SMP-like) substances were the dominant components in the organic fouling layer in a long-term ultrafiltration of surface water used as a drinking water source. A decrease of protein/protein-like substances and an increase of SMP-like substances with the filtration time were found, which could be attributed to the transition from proteins to SMP in the fouling layer. Thus, the increase of SMP-like substances in the fouling layer would play a significant role on the accumulation of irreversible fouling.
\end{abstract}

(C) 2012 Elsevier B.V. All rights reserved.

\section{Introduction}

Membrane filtration has been extensively used for water treatment in the past decade [1-3]. In particular, low pressure membranes (LPMs) which are operated at relatively low transmembrane pressures (TMPs, less than 100-200 kpa, typically) with nominal pore sizes of 10-200 $\mathrm{nm}$ are becoming more attractive for the drinking water works in China due to various reasons, such as the strict regulatory requirements for the effluent quality, operation easiness, limited footprints and competitive cost [4,5]. However, an important challenge to the applications of LMPs at different scales is the membrane fouling which causes a great reduction in the membrane productivity, leading to a severe filtration flux decline [6]. Therefore, it is important to identify the foulants on the membrane, especially the composition of natural organic matters (NOMs) of the foulants.

\footnotetext{
* Corresponding authors. Tel./fax: +86 1062849138.

E-mail addresses: fengxiao@rcees.ac.cn (F. Xiao), wgds@rcees.ac.cn (D.-s. Wang).
}

Membrane fouling is a complex issue [7,8]. NOMs are widely recognized as the major foulants to reduce the permeate flux in membrane filtration. Using hollow fiber microfiltration (MF) and ultrafiltration (UF) membranes, Huang et al. [9] compared the fouling behaviors of polyvinylidene fluoride (PVDF) and polyether sulfone (PES) LPMs by different natural water. The study revealed that certain fractions of NOM, not all organic matters, could affect the fouling. Varbanets et al. [10] found that hydrophobic humic acids made an increase in resistance at ultra-low pressure UF membrane system by investigating seven types of water. Jermann et al. [11] set up a series of dead-end UF batch experiments to observe the fouling of humic acid, alginate and kaoline. They reported that humic substances caused severe irreversible fouling due to adsorption, while alginate should have a most detrimental effect on membrane fouling, but mostly reversible. Through investigating the fouling behavior of natural water in three different types of MF and UF membranes, Yamamura et al. [12] revealed that carbohydrates were dominant in the membrane foulants regardless of the types of membranes. Other researchers $[13,14]$ considered that a high content of hydrophilic fraction or hydrophilic neutral 
fraction in the nature water caused serious flux decline, by using hydrophobic and hydrophilic MF and UF membranes on the NOM isolated from different surface water. However, all these studies focused on identifying the membrane organic foulants at the end of few filtration cycles in a batch or bench-scale system, which could cause the results of previous studies on the major foulants to be inconsistent since the organics accumulation on the membrane is a long-term process. More importantly, the fate and transfer characteristics of the organic foulants in the fouling layer are not addressed by previous studies. Hence, it merits more efforts to identify the organic foulants and investigate the NOM characteristics in a large scale facility with a long time filtration.

In order to improve the performance of LPMs, inline coagulation as a successful pretreatment option to control the fouling has been incorporated into the full-scale facilities [15,16]. Coagulation can destabilize contaminants and form the hydrophobic aggregates which can reduce the particle affinity to the hydrophilic membrane surface, resulting in a reduced fouling [17]. A previous study [18] investigated the performance of polyvinylidene fluoride (PVDF) and polypropylene (PP) microfiltration (MF) membrane hybrid with inline coagulation, showing that the membrane material is important to the fouling behavior. However, results can only reflect a short-term experimental run under the laboratory conditions.

In this study, a ultrafiltration (UF) low pressure membrane (LPM) made of polyvinyl chloride (PVC) was employed in a full scale facility for a long term operation in Nantong, Jiangsu Province, China. The membrane filtration was used with an inline poly-ferric sulfate (PFS) coagulation treatment. The fouling behavior of the low pressure PVC UF membrane process was investigated during a whole year operation. We identified the organic foulants by examining the desorbed organic matters from the fouled membranes using attenuated total reflectance-fourier transform infrared spectroscopy (ATR-FTIR), high-pressure size-exclusion chromatography (HPSEC) and fluorescence excitation-emission matrix (EEM) spectrometry and focused on the role and transformation of organic constituents in the fouling layer with time by using fluorescence regional integration (FRI) method. In addition, the evolutions of the surface morphology of the membranes were characterized by scanning electronic microscopy (SEM) and atomic force microscopy (AFM). The results obtained in this study provide a new insight into characteristics of organic foulants during a long time operation.

\section{Materials and methods}

\subsection{UF membrane set-up and operation}

Continuous operation of PVC UF-LPM was carried out at Lujing (Nantong) water supply plant (Jiangsu, China). It was the first plant in China to integrate inline coagulation with UF membrane filtration, as demonstrated in Fig. 1. The source water was from Yangtze River. Table 1 presented the characteristics of the waters in 2010. After coagulation with a dosage of $10-15 \mathrm{mg} / \mathrm{L}$ of PFS, the coagulated water was treated with the PVC UF membrane modules without sedimentation.

The plant was equipped with the hollow-fiber UF membrane modules made of PVC that had a filtration area of $35 \mathrm{~m}^{2}$ with a nominal pore size of $0.01 \mu \mathrm{m}$, molecular weight cutoff (MWCO) of $50 \mathrm{kDa}$ (Litree Co., Hainan, China). The contact angle of the PVC membrane was measured as $33.67 \pm 0.46$, indicating a hydrophilic property [19-21]. The UF filtration system consisted of 10 sets and each set included 104 modules. Filtration was carried out in a dead-end mode with outside-in flow pattern. The designed flux for each module was more than $30 \mathrm{~L} / \mathrm{m}^{2} \mathrm{~h}$ (LMH) under around $4 \mathrm{~m}$ hydraulic pressure. The running cycle was $23 \mathrm{~h}$ filtration.
Hydraulic backwash was performed $30 \mathrm{~s} / \mathrm{h}$ with a flux of $60 \mathrm{LMH}$ (inside-out) and air bubble intensity of $90 \mathrm{~m}^{3} / \mathrm{m}^{2} / \mathrm{h}$. The hydraulic retention time and sludge retention time were about 0.768 and $3 \mathrm{~h}$, respectively. An additional maintenance cleaning with sodium hypochlorite ( $\mathrm{NaClO}, 200 \mathrm{ppm}$ ) was carried out every two weeks in order to keep a continuous operation. The whole system was performed from January to December 2010. Fouled membranes were sampled randomly in March 30, June 30, September 30 and December 30.

The degree of membrane fouling was evaluated by membrane filtration resistance calculated by the following equation:

$J=\Delta P / \mu R$

where $J$ was membrane permeate flux (LMH), $\Delta P$ was the transmembrane pressure difference (Pa), $\mu$ was the viscosity (Pa s), and $R$ was the total membrane filtration resistance $\left(\mathrm{m}^{-1}\right)$.

\subsection{Desorption of the organic matter from fouled membrane}

To investigate the constituents responsible for membrane fouling, organic matters were desorbed from the fouled membranes with the method of Kimura et al. [5]. The fouled fibers were manually wiped with a lab sponge to remove accumulated cake. Desorption of organic matters from the fouled fibers was carried out by soaking with acid solution (hydrochloric acid $(\mathrm{HCl})$, $0.01 \mathrm{~mol} / \mathrm{L}$ ) firstly and then alkaline solution (sodium hydroxide $(\mathrm{NaOH}), 0.01 \mathrm{~mol} / \mathrm{L})$ for $24 \mathrm{~h}$, respectively. The extraction efficiency was above $90 \%$ by checking the mass balance with three model organic matters (Supplementary Table S1). The solutions were then filtered with $0.45 \mu \mathrm{m}$ cellulose fabric membrane. For further analysis, total organic carbon (TOC) and ultraviolet (UV) absorbance at a wavelength of $254 \mathrm{~nm}$ were measured.

\subsection{Characterization of NOM and membrane}

\subsubsection{Determination of the dissolved organic matter (DOM) fractions}

The DOM fractions in the waters were characterized by the method of resin fractionation [22]. XAD-8 and XAD-4 resins (Amberlite, Sigma-Aldrich Co., USA) were used to fractionate DOM as follows: (1) The pre-filtered sample (by $0.45 \mu \mathrm{m}$ fabric membrane) was first passed through XAD-8 resin without any $\mathrm{pH}$ adjustment to isolate hydrophobic bases $(\mathrm{HoB})$ and hydrophobic neutral (HoN). (2) HoB was obtained by back-washing the XAD8 resin immediately with 10 bed-volumes of $0.1 \mathrm{~mol} / \mathrm{L}$ phosphoric acid at 15 bed-volumes/h. The hydrophobic neutral (HoN) could not be desorbed by phosphoric acid and retained in the resin. Phosphoric acid $\left(\mathrm{H}_{3} \mathrm{PO}_{4}\right)$ was selected because of its minimum impact on the dissolved organic carbon (DOC) measurement compared to $\mathrm{HCl}$ or hydrogen nitrate $\left(\mathrm{HNO}_{3}\right)$. (3) The first effluent of XAD-8 column was adjusted to $\mathrm{pH} 2$ by $85 \% \mathrm{H}_{3} \mathrm{PO}_{4}$ and added into this XAD-8 resin column again. The hydrophobic acid (HoA) was adsorbed. (4) The second effluent from XAD-8 column was passed through XAD-4 resin. The fraction adsorbed by this resin could be described as weakly hydrophobic acid (WHoA), (5) organics contained in the XAD- 4 effluent (not retained by both XAD- 8 and XAD- 4 resins) were named hydrophilic matter (HiM). The resins were cleaned and conditioned as described by Leenheer [23].

\subsubsection{High pressure size exclusion chromatography (HPSEC)}

Molecular weight (MW) distributions were determined with a HPSEC method. A Waters liquid chromatography system was used for MW analysis, including Waters 2487 Dual $\lambda$ Absorbance Detector, Waters 1525 pump system. Separation was performed with a Shodex KW 802.5 column (Shoko Co., Japan). The mobile phase, Milli-Q water buffered with $5 \mathrm{mM}$ phosphate to $\mathrm{pH} 6.8$, and $0.01 \mathrm{~mol} / \mathrm{L}$ sodium chloride $(\mathrm{NaCl})$, was filtered through a $0.22 \mu \mathrm{m}$ 


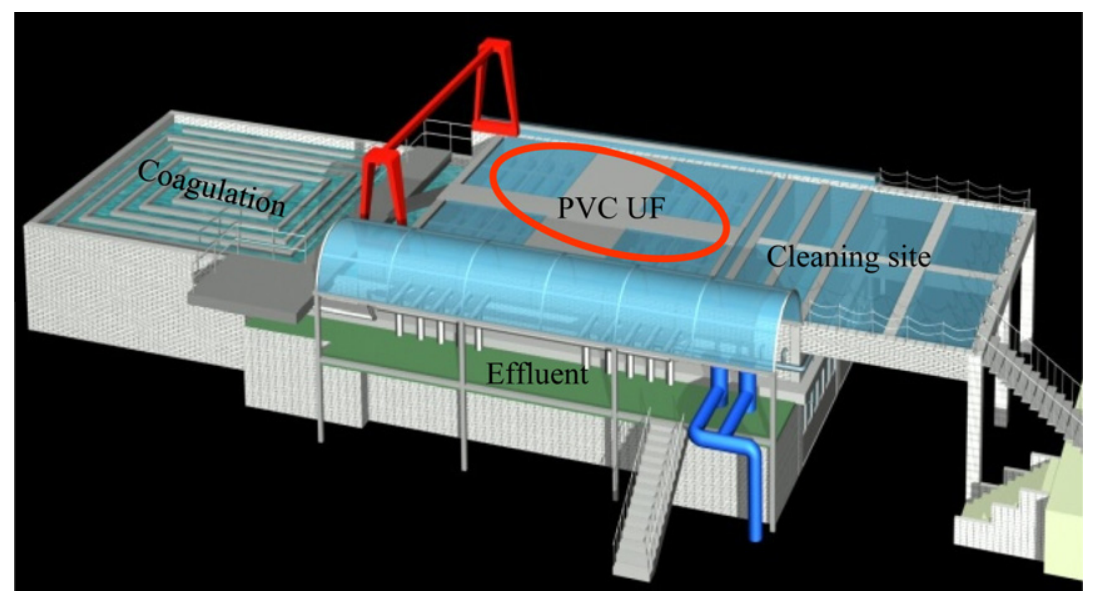

Fig. 1. The schematic of the PVC UF-LPM filtration facility integrated with inline coagulation.

Table 1

The characteristics of the source water, effluent after coagulation and permeate.

\begin{tabular}{|c|c|c|c|}
\hline & Source water & Effluent after coagulation & Membrane permeate \\
\hline Turbidity (NTU) & $10-240$ & $1.69-67.8$ & $0.08-0.37$ \\
\hline $\mathrm{pH}$ & $7.22-8.27$ & $7.34-7.89$ & $7.64-7.91$ \\
\hline $\mathrm{DOC}(\mathrm{mg} / \mathrm{L})$ & $1.55-2.24$ & $1.43-2.1$ & $1.41-2.00$ \\
\hline $\mathrm{UV}_{254}(1 / \mathrm{m})$ & $0.032-0.056$ & $0.016-0.045$ & $0.025-0.038$ \\
\hline Temperature $\left({ }^{\circ} \mathrm{C}\right)$ & $3-31.5$ & $5-10$ & $5-10$ \\
\hline The total coliform count (MNP/100 ml) & $130-540$ & $5.1-16$ & ND \\
\hline
\end{tabular}

fabric membrane, and then degassed for $30 \mathrm{~min}$. The flow rate was $0.8 \mathrm{ml} / \mathrm{min}$ and the injection volume was $200 \mu \mathrm{l}$. Polystyrene sulphonate (PSS) standards (Sigma-Aldrich, USA) with MWs of 1.8 , $4.2,6.5$ and $32 \mathrm{kDa}$ were used to calibrate the relationship between MW and retention time [24].

\subsubsection{Three-dimensional fluorescence excitation-emission matrix spectrometry (3D-EEM)}

3D-EEM spectra (F-7000, Hitachi, Japan) were obtained by collecting excitation and emission spectra of NOM source over a range (excitation wavelength $\left(E_{x}\right)$ between 200 and $400 \mathrm{~nm}$, emission wavelength $\left(E_{m}\right)$ between 250 and $550 \mathrm{~nm}$, at $5 \mathrm{~nm}$ sampling intervals). Instrumental parameters were excitation and emission slits, $5 \mathrm{~nm}$; response time, $0.01 \mathrm{~s}$; and scan speed, $2400 \mathrm{~nm} / \mathrm{min}$. Data were analyzed with Sigma Plot software. Spectral subtraction was performed to remove blank spectra mainly caused by Raman scattering.

According to the research [25], the EEM spectra could be divided into five regions, which represented humic acid-like, fulvic acid-like, tyrosine-like, tryptophan-like, and soluble microbial byproduct-like (SMP-like, which is defined as soluble extracellular polymeric substances (EPS), mainly contain small carbonaceous compounds derived from the original substrate [26]) organics respectively. These five organic compounds can be summarized to three major organics, i.e. humic substances, aromatic proteins and SMP-like substances (Supplementary Table S2). As stated by Chen et al. [25], the beneath EEMs within selected regions could represent the cumulative fluorescence response of DOM with similar properties. Therefore, quantification of the EEM spectra could be achieved by the fluorescence regional integration (FRI) method.

\subsubsection{Attenuated total reflectance-fourier transform infrared spectroscopy (ATR-FTIR)}

ATR-FTIR spectrometry provided insights into the nature of the foulants in membrane. The ATR-FTIR (Magna-IR 750, Nicolet, USA) was used with a resolution of $4 \mathrm{~cm}^{-1}$ in the range of $600-$
$4000 \mathrm{~cm}^{-1}$, to provide the information of the functional groups of the foulants on membrane. Before the FTIR analysis, the samples were totally air dried in clean plastic bags at room temperature. The dried samples were then cut to obtain the flat external surface. Samples exposed to infrared light absorbed energy corresponding to the vibrational energy of atomic bonds. The characteristic of functional groups absorbing energy at specific wavelengths can be used to identify the unknown matters.

\subsubsection{Scan electronic microscopy (SEM) and Atomic force microscopy (AFM) \\ SEM (LEO-1530, Germany) analysis was carried out to observe} the surface and cross-section of new and fouled membranes. All samples were completely dried in clean plastic bags at room temperature. For cross-section observation, the membrane fibers were frozen with the liquid nitrogen and fractured to obtain the sharp edge. Then all samples would be coated with gold ( $\mathrm{Au})$ and examined at $30 \mathrm{kV}$ accelerating voltage for SEM analysis [27].

The AFM (EX-1, DI CO, USA) made by digital instruments was employed and silicon nitride $\left(\mathrm{Si}_{3} \mathrm{~N}_{4}\right)$ cantilever with integrated pyramidal tips (OTR8-35) were used to investigate the morphology change of the new and fouled membranes. The membrane surface was imaged in tapping mode. All samples were dried in clean plastic bags at room temperature. The sample specimen was fixed on a slide glass and was measured with a scan size of $2 \mu \mathrm{m} \times 2 \mu \mathrm{m}$. Data were collected and analyzed by the software (Nanoscope V5.31).

\subsubsection{Other analytic methods}

DOC was measured with a TOC analyzer (TOC-VCPH, SHIMADZU, Japan) for the desorption solutions extracted by $\mathrm{HCl}$ and $\mathrm{NaOH}$ solutions. UV absorbance at $254 \mathrm{~nm}\left(\mathrm{UV}_{254}\right)$ was analyzed using a spectrometer (U-2910, Hitachi, Japan). All of the samples were filtered through a $0.45 \mu \mathrm{m}$ cellulose fabric membrane before the measurements. 


\section{Results and discussion}

\subsection{Coagulation pretreatment}

Table 1 summarized the range of important parameters for water quality monitoring. Apparently, the raw water of Yangtze river has a low DOC and a greatly varied turbidity. After coagulation, the turbidity substantially decreased to $4.42 \%$ (average), the removal of coliform was more than $95 \%$ with bacteria decreasing to $55 \%$. While DOC and $\mathrm{UV}_{245}$ just declined to $95.33 \%$ and $78.26 \%$ (average), respectively. Coagulation was considered as a destabilization process of colloidal particles, involving two primary mechanisms: (1) absorption to produce charge neutralization (destabilization), and (2) sorption to permit interparticle bridging $[28,29]$. As mentioned previously, it played an important role in removal of colloidal particles and a little effect on NOM removal. During coagulation-ultrafiltration process, the loose formation of flocs with good permeability on membrane surface was beneficial to hydraulic backwashing as well as reducing the fouling rate.

In addition, the resin fractionation method [22] was employed to determine the specific fractional compositions of raw water and water after coagulation (Table 2 ). The main components of organic matters were $\mathrm{HoA}$ and $\mathrm{HiM}$ with the contents of 0.58 and $0.60 \mathrm{mg} / \mathrm{L}$, respectively. The content of WHoA was $0.32 \mathrm{mg} / \mathrm{L}$, while HoB were $0.29 \mathrm{mg} / \mathrm{L}$. HoN had the smallest DOC content with $0.15 \mathrm{mg} / \mathrm{L}$. After coagulation, the contents of HoN and WHoA were almost the same. HoB and HiM reduced to 0.21 and $0.52 \mathrm{mg} / \mathrm{L}$, with removal rate of $27.59 \%$ and $13.33 \%$, respectively. But the percentage of HoA increased by $10.34 \%$. It indicated that coagulation could remove a certain amount of $\mathrm{HoB}$ and $\mathrm{HiM}$ by formation of flocs.

\subsection{Membrane performance}

The facility was operated very stably in terms of water quality. It can be noted that the coliform bacteria cannot be found in the filtration permeate, and the turbidity removal efficiency was more than $99 \%$ (Table 1).

Fig. 2 depicted the changes in flux and the total resistance $\left(R_{t}\right)$ during one year filtration. The temperature of source water was large variation from 3 to $31.5^{\circ} \mathrm{C}$, and the data plotted in Fig. 2 were adjusted to $20^{\circ} \mathrm{C}$ equivalent values considering the influence of water viscosity on filtration resistance. The changes could be divided into three stages according to the variation of permeate flux. From January to April, flux was around $31 \mathrm{LMH}$ and $R_{t}$ almost kept the $2-2.5 \times 10^{12} \mathrm{~m}^{-1}$, indicating a good start-up of the facility. After April, the flux was suddenly increased and reached the maximum flux at 34.3 LMH in July with a lower viscosity. During this period, the flux dropped only marginally. However, $R_{t}$ increased steadily at almost a constant rate of $4.11 \%$ per month. The final stage was from August to December. However, the flux decreased sharply from 33.98 to $23.28 \mathrm{LMH}$, only being $75.13 \%$ of initial flux. It also can be found that $R_{t}$ substantially increased from $2.11 \times 10^{12}$ to $3.26 \times 10^{12} \mathrm{~m}^{-1}$ during the whole filtration process. Apparently, the membrane fouling aggravated, leading to a substantial flux decrease together with the $R_{t}$ increase. Therefore, membrane resistance would be a better index for fouling evalua-

Table 2

The fractions of NOM in waters (average value).

\begin{tabular}{lcl}
\hline & Raw water & Effluent after coagulation \\
\hline HoN $(\mathrm{mg} / \mathrm{L})$ & $0.15 \pm 0.056$ & $0.14 \pm 0.032$ \\
HoB $(\mathrm{mg} / \mathrm{L})$ & $0.29 \pm 0.081$ & $0.21 \pm 0.006$ \\
HoA $(\mathrm{mg} / \mathrm{L})$ & $0.58 \pm 0.046$ & $0.64 \pm 0.001$ \\
WHoA $(\mathrm{mg} / \mathrm{L})$ & $0.3 \pm 0.029$ & $0.33 \pm 0.023$ \\
HiM $(\mathrm{mg} / \mathrm{L})$ & $0.60 \pm 0.03$ & $0.52 \pm 0.023$ \\
\hline
\end{tabular}

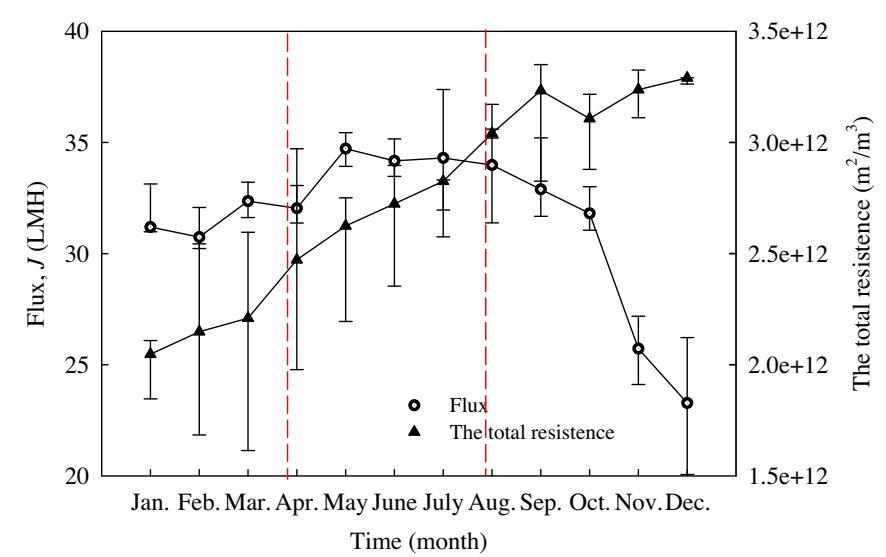

Fig. 2. Variation of flux and the total resistance during one year operation.

tion compared to the flux. Before the chemical cleaning, the membrane modules were taken out in March 30, June 30, September 30 and December 30 . The organics were extracted in order to identify the foulants and find out the fouling kinetics. Visual inspection at the end of the operation revealed that the accumulation of cake on the membrane surface was not significant, indicating the good performance of low-pressure PVC UF membrane in combination with prior inline coagulation.

\subsection{Morphological analysis}

\subsubsection{Scan electronic microscopy (SEM) observation of membrane}

The samples of virgin and fouled membranes were observed with SEM. As shown in Fig. 3a and b, the surface of virgin membrane was rather clean and smooth. By contrast, it could be obviously observed that the membrane surface was fouled seriously after one year operation. A cake layer was formed by the foulants attached to the membrane surface (Fig. $3 \mathrm{c}$ ) and the pores in the fouled membrane surface were blocked by some small particulates (Fig. 3d), while the channels became narrow, causing a significant flux decline [30].

\subsubsection{Atomic force microscopy (AFM) analysis}

Fig. 4 demonstrated the AFM images of the virgin and fouled membrane surface. The fouled membrane surface provided a relative high surface topographical view and presented more zigzag of the section profile, which was seriously fouled in comparison to the virgin membrane surface. According to the results, the roughness of the surface was improved owing to the deposited foulants which could form a cake layer. Fig. 5 displayed the variation of roughness at different months in one year operation. Apparently, the average roughness of the formed layer increased from 6.15 to $7.445 \mathrm{~nm}$, comparing with $5.688 \mathrm{~nm}$ of the new membrane. Therefore the cake layer gradually became thicker, leading to a higher membrane resistance and flux declined.

According to the images of SEM and AFM, tiny particles could enter into the pores, leading to pores blocked and channels narrow. Other foulants may directly deposit on the membrane surface, especially on these existing foulants and then a cake layer was formed in a sequence [31]. The built-up foulants significantly changed the membrane morphology, resulting in an increase of the surface roughness.

\subsection{Identification of membrane organic foulants}

3.4.1. Characterization of the foulants desorbed by chemical cleaning

Table 3 summarized DOC of the desorbed solutions with $0.01 \mathrm{~mol} / \mathrm{L} \mathrm{HCl}$ and $0.01 \mathrm{~mol} / \mathrm{L} \mathrm{NaOH}$ every three months. The 


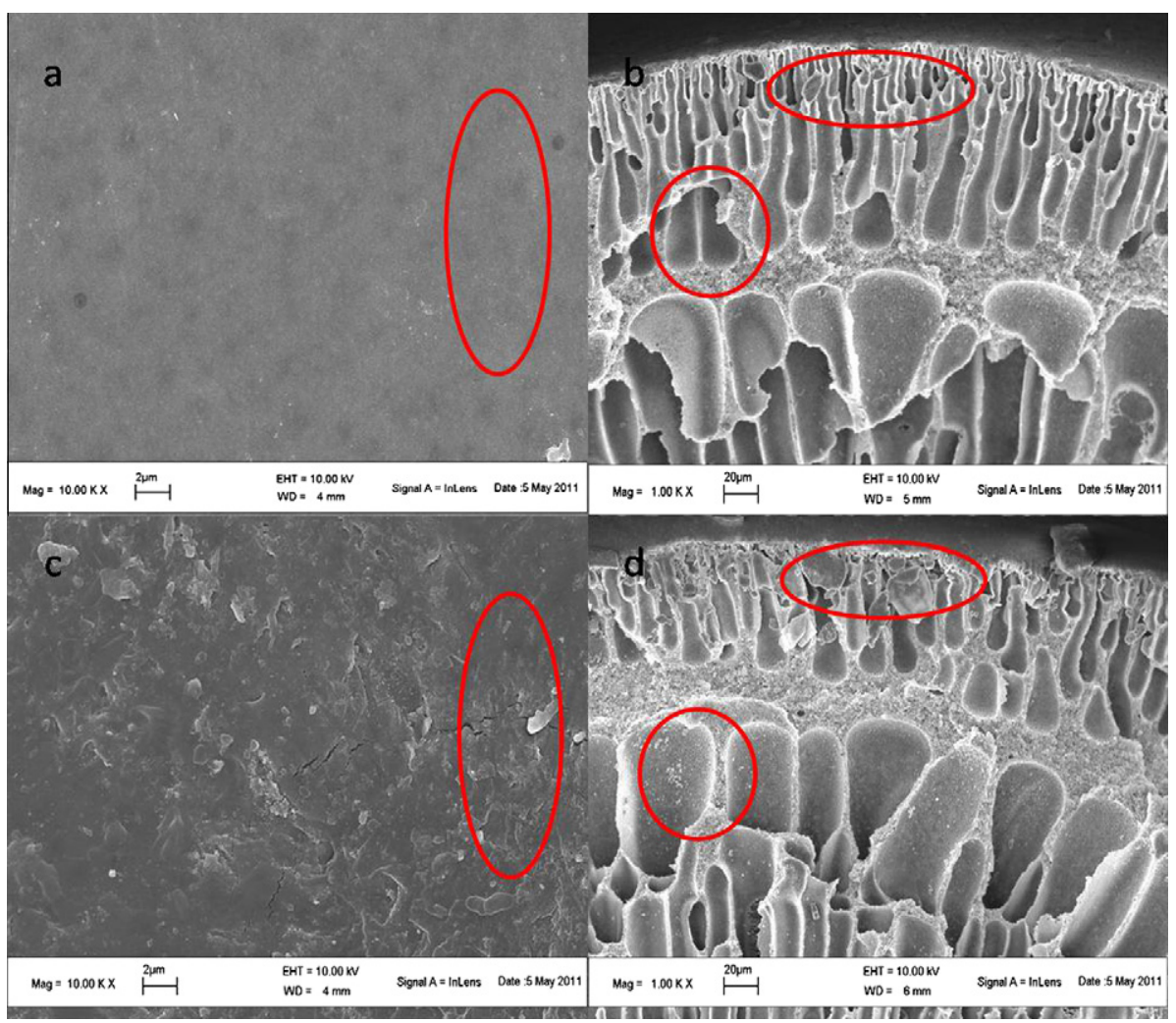

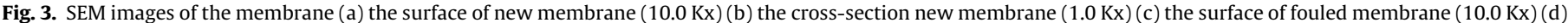
the cross-section fouled membrane $(1.0 \mathrm{Kx})$.
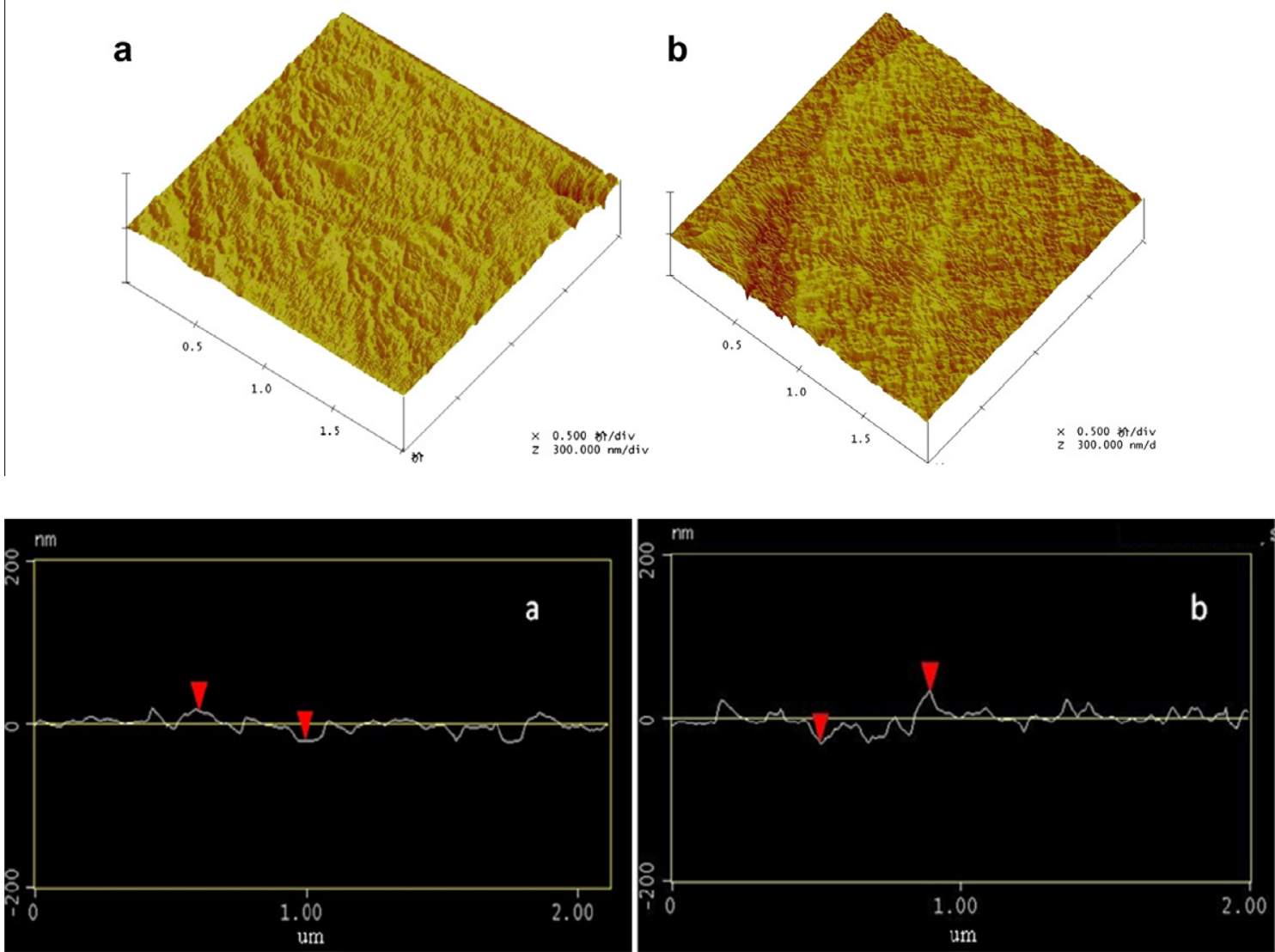

Fig. 4. AFM images (a) new membrane; (b) fouled membrane; (c) cleaned membrane. 


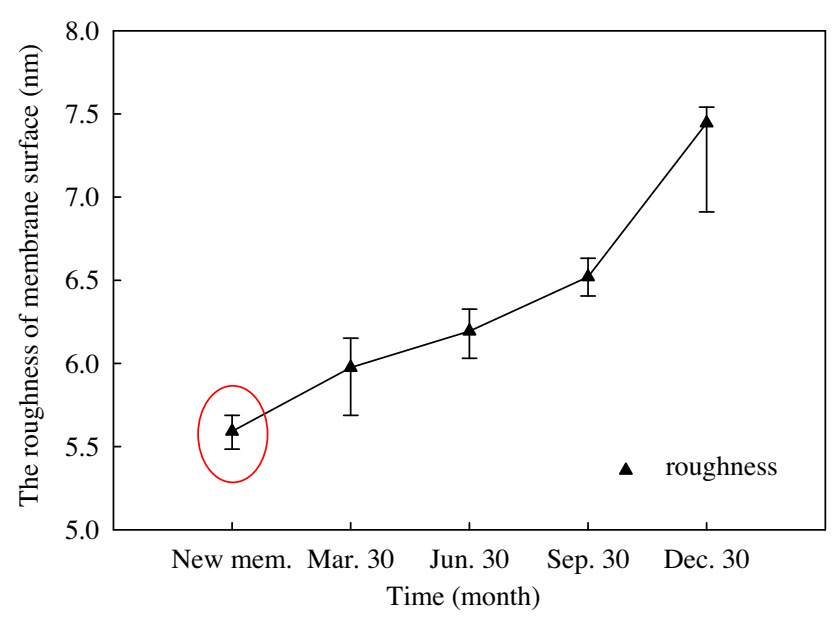

Fig. 5. The variation of roughness with time.

organic matters desorbed by $\mathrm{HCl}$ increased from 0.1405 to $0.5121 \mathrm{mg} / \mathrm{L}$, while the organic matters eluted by $\mathrm{NaOH}$ were 25 times higher than those by $\mathrm{HCl}$. But the values of $\mathrm{UV}_{254}$ changed randomly. Furthermore, the total contents of eluent were rising from 0.824 to $1.658 \mathrm{mg} / \mathrm{L}$, which demonstrated accumulation of organic foulants on membrane with operation time.

\subsubsection{High pressure size exclusion chromatography (HPSEC)}

Fig. 6 displayed HPSEC responses of desorbed solutions after chemical cleaning, which had subtracted the blanks of $\mathrm{NaOH}$ and $\mathrm{HCl}$ solutions. These results portrayed both the physical and chemical properties of the desorption solution. Apparently, there were three main peaks in the solution desorbed by $\mathrm{NaOH}$ solution. The first peak corresponded to humic substances, humic and fulvic acid ( $\pm 1000 \mathrm{Da}$ ) [32]. Proteins, polysaccharides with a characteristic of high MW (>10000 Da) were corresponded to the second and third peaks, which showed a much higher responses than the humic peak [32]. However, the solution desorbed by $\mathrm{HCl}$ just had only one high MW peak with a relatively low proteins or polysaccharides response. The results indicated that $\mathrm{NaOH}$ could be more effective to remove organic matters compared to $\mathrm{HCl}$. The higher MW macromolecular matters, such as protein and polysaccharides, had a high UV intensity peak, indicating that they would play a more significant role in causing membrane fouling. Meanwhile, humic substances had a relatively low UV peak, demonstrating humic substances may not have a major contribution to the PVC membrane fouling.

\subsubsection{Three-dimensional fluorescence excitation-emission matrix spectrometry (3D-EEM)}

3D-EEMs of desorbed solution were measured and the results were illustrated in Fig. 7. Desorption solution by $\mathrm{HCl}$ showed just only one maximum peak at $E_{x}=250$ and $E_{m}=365 \mathrm{~nm}$. According

Table 3

Characteristics of organic foulants desorbed by chemical solutions.

\begin{tabular}{llll}
\hline Date & Index & $0.01 \mathrm{~mol} / \mathrm{L} \mathrm{HCl}$ & $0.01 \mathrm{~mol} / \mathrm{L} \mathrm{NaOH}$ \\
\hline March-10 & DOC $(\mathrm{mg} / \mathrm{L})$ & 0.1405 & 0.6838 \\
& UV254 $(\mathrm{L} / \mathrm{cm})$ & 0.0141 & 0.0109 \\
June-10 & DOC $(\mathrm{mg} / \mathrm{L})$ & 0.2334 & 0.6904 \\
& UV254 $(\mathrm{L} / \mathrm{cm})$ & 0.005 & 0.013 \\
September-10 & DOC $(\mathrm{mg} / \mathrm{L})$ & 0.2532 & 0.9711 \\
& UV254 $(\mathrm{L} / \mathrm{cm})$ & 0.013 & 0.008 \\
December-10 & DOC $(\mathrm{mg} / \mathrm{L})$ & 0.5121 & 1.146 \\
& UV254 $(\mathrm{L} / \mathrm{cm})$ & 0.014 & 0.013 \\
\hline
\end{tabular}

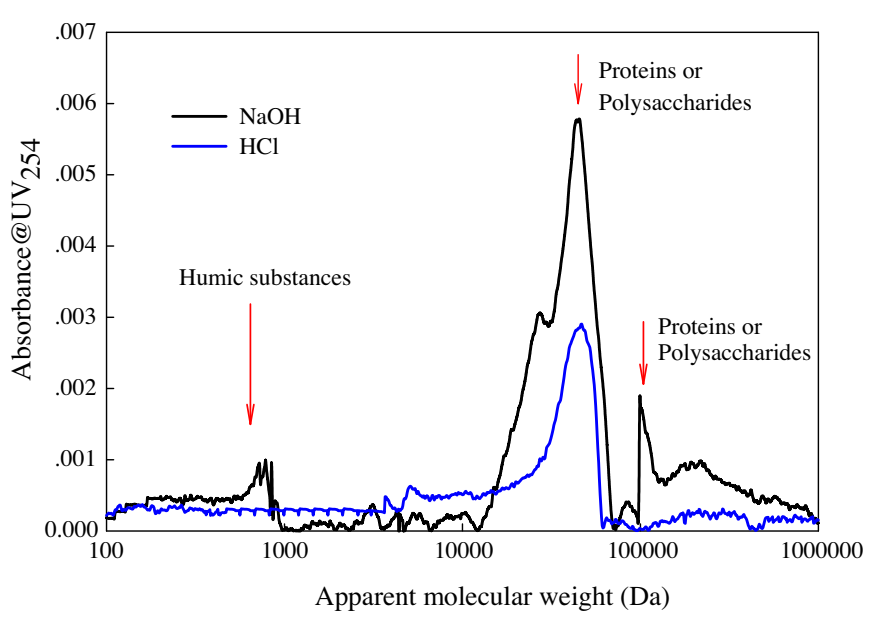

Fig. 6. HP-SEC responses of organic foulants in the desorption solutions.

to the previous research [25], this peak corresponded to the aromatic protein II zone. Desorption solution by $\mathrm{NaOH}$ showed a similar maximum peak at $E_{x}=225$ and $E_{m}=344 \mathrm{~nm}$, corresponding to aromatic protein-like substances too. Baker [33] reported that that fulvic-like fluorescence occurs at $E_{x}=320-340$ and $E_{m}=410-$ $430 \mathrm{~nm}$, and humic-like fluorescence occurs at $E_{x}=370-390$ and $E_{m}=460-480 \mathrm{~nm}$. Generally, humic-like substances exhibit a fluorescence intensity maximum at higher excitation/emission wavelengths compared to protein-like substance (maximum at lower excitation/emission wavelength [34]. Therefore, the aromatic protein-like substances can be inferred to have a very significant fouling potential. In addition, soluble microbial by-product (SMP) like also can contribute to the fouling to a certain degree. SMP-like substances were related to biological activities, which were composed of tyrosine and/or protein-like, tryptophan and/or protein-like. However, humic substances can be found little contribution to the fouling, which were consistent with the results of HPSEC.

\subsubsection{Attenuated total reflectance-fourier transform infrared spectroscopy (ATR-FTIR) analysis}

Three fouled membrane fiber samples had been investigated for ATR-FTIR spectra analysis. The results were presented in Fig. 8 (the background spectrum had been digitally subtracted). There were significant similarities in the spectra obtained for the three samples. In these spectra, peaks near $1000 \mathrm{~cm}^{-1}$ were significant. Absorption in this region indicated the presence of polysaccharide-like/polysaccharide (SMP-like) in the foulants [26,35]. A strong absorption band was observed between 1076 and $1094 \mathrm{~cm}^{-1}$, which was assigned to $\mathrm{C}-\mathrm{O}$ bond of ethers or carboxylic acid, probably polysaccharide [35]. Three weak bands were observed near 1740,1650 and $1543 \mathrm{~cm}^{-1}$. These bands correspond to carbonyl, amide I and amide II bands of an amide structure, which would be indicative of proteins $[26,36]$. All the spectra exhibited IR peaks of carboxylic group (near $1250 \mathrm{~cm}^{-1}$ ), carboxylic acid (around $1430 \mathrm{~cm}^{-1}$ ), which required a further investigation to identify. Therefore, the results of ATR-FTIR suggested that proteins and polysaccharides (SMP-like) [26] were the dominant components in the foulants, while humic substances were found little contribution to the fouling.

\subsubsection{The accumulation of organic matters in membrane}

Fig. 9 described the variation of DOC in the desorbed solution with operation time. The overall trend was rising from 0.824 to $1.658 \mathrm{mg} / \mathrm{L}$. It illustrated that organic matters would accumulate on membrane surface during the filtration. From EEM results, the 

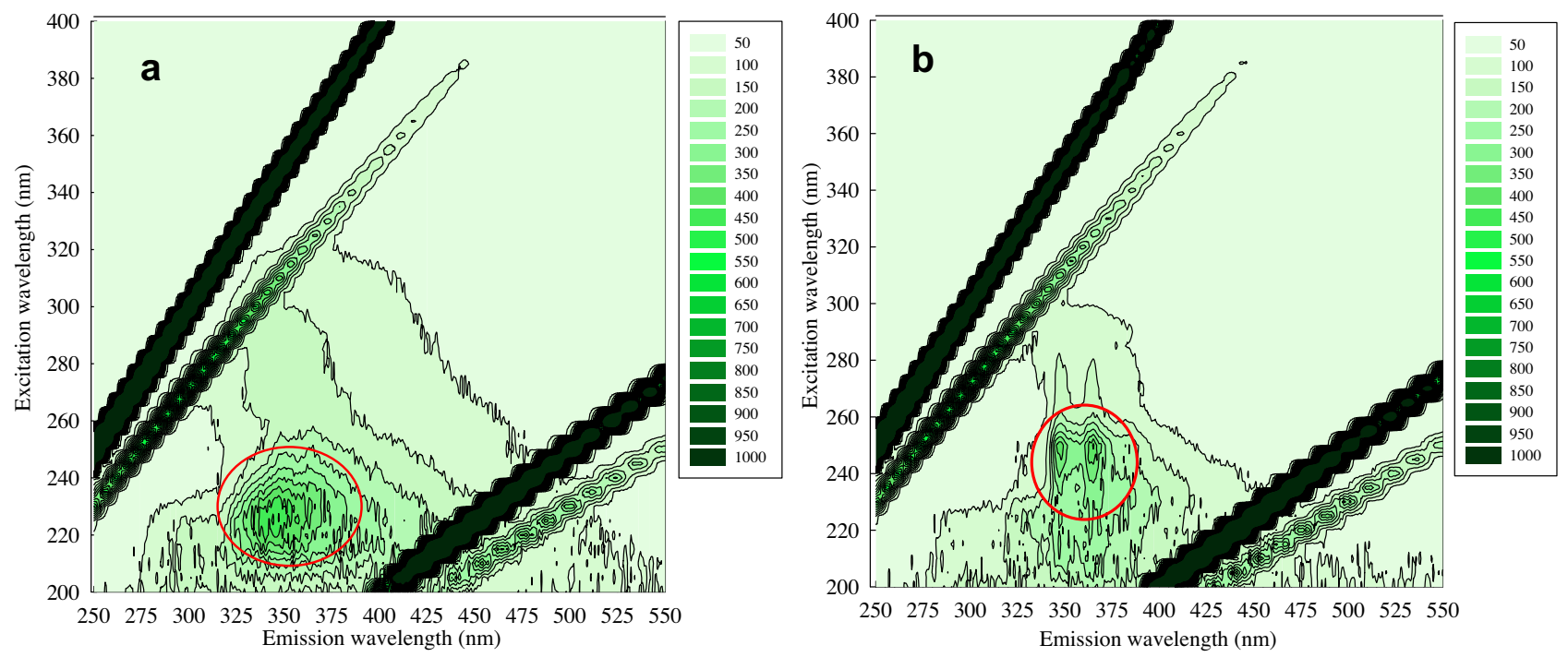

Fig. 7. The EEMs of organic compounds in (a) desorption solution by $\mathrm{NaOH}$, (b) desorption solution by $\mathrm{HCl}$.

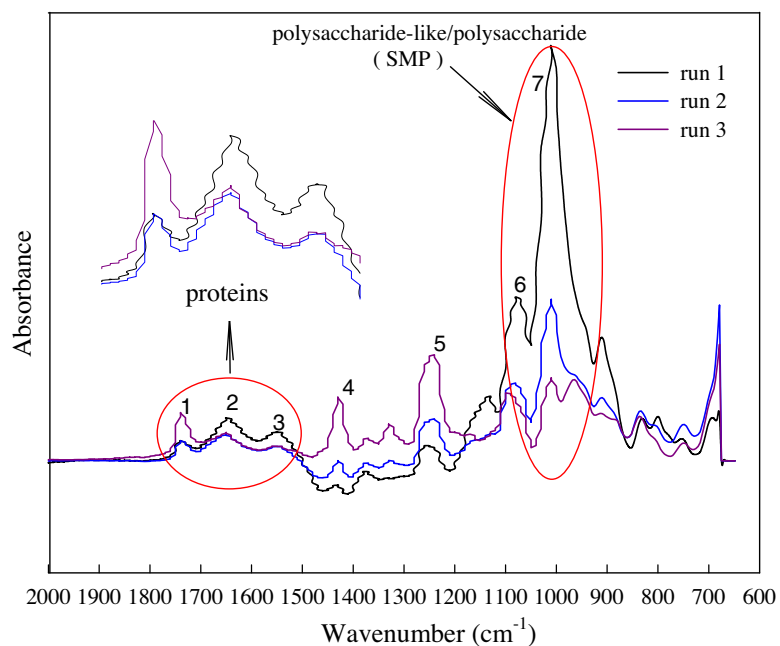

Fig. 8. ATR-FTIR spectra of foulants on membrane.

DOC mainly came from three typical organics-the aromatic protein, SMP-like substance and humic substances. In order to find out how these organic compounds changed during the accumulation process, we calculated the percent fluorescence response $P_{i, n}$ of three different regions (Supplementary Table S3) according to the method mentioned previously [25]. From Fig. 9 it can be seen that aromatic protein had a highest percentage of EEM response which exceeded more than $75 \%$, indicating a highly correlation with irreversible fouling under the operation condition. It is very interesting to observe that aromatic protein accumulated in membrane declined with time, from $90.22 \%$ to $79.78 \%$. At the same time, the response of SMP increased from $7 \%$ to $20 \%$, and the humic substances kept a very stable situation around $3 \%$. Again, humic substances were not found to be important in the formation of the combined fouling layer, which is consistent with previous results of HPSEC and ATR-FTIR. Peldszus et al. [37] also reported a very similar result that protein content had a key role in membrane irreversible fouling, while humic substances were not found to be important in the formation of the combined fouling layer.

It appeared that fast increase of SMP-like substances in fouling layer played a significant role on the accumulation of irreversible fouling. This increase may be caused by two reasons. One is the
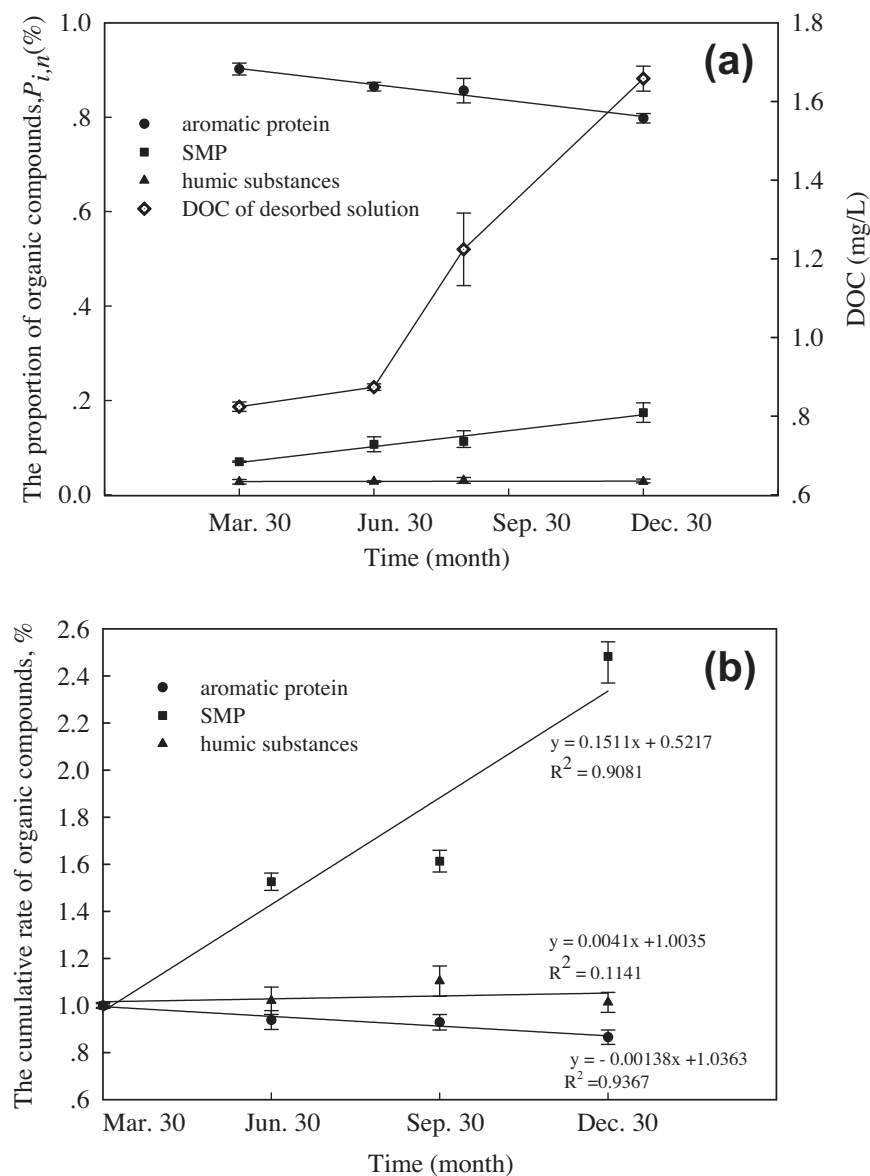

Fig. 9. The accumulation of organic matters in different months (a) according to fluorescence regional integration (FRI) method, calculated the percent response $P_{i, n}$ of three regions; (b) The cumulative rate of organic compounds.

variation of the source water. The other is the transformation of the fouling layer. However, the organic matters in source water had a fixed composition with the proportion of aromatic protein, SMP-like substances and humic substances at 7:2:1 (Supplementary Fig. S1). Therefore, the increase of SMP-like substances was 
highly attributed to the transition from proteins to SMP as the total proportion of protein/protein-like substances and SMP substances kept almost unchanged. As showed in Fig. 9, the increase of SMP in the combined fouling layer would lead to a higher membrane resistance and a more severe fouling. Hence, reducing protein content in the source or controlling the transition from protein to SMP would be a better way to alleviate the membrane fouling.

\section{Conclusions}

In this study, the identification and accumulation effects of organic foulants on the low pressure PVC UF membrane process in a full scale facility was investigated after a long term operation. According to the results, the following conclusions can be drawn:

(1) In general, the low-pressure PVC UF membrane performed successfully in a long term operation. Coagulation could remove a large part of particles and had a limited effect on eliminating organic foulants. After one year operation, the flux declined considerably with the increase in total resistance due to accumulation of the organic foulants on membrane.

(2) SEM and AFM observations revealed that cake layer and pores blocked were responsible for the flux decline. The fouled membrane exhibited a higher topography compared to the new membrane. The roughness of fouled membrane surface increased with filtration time, leading to a higher resistance.

(3) The organic foulants were eluted and analyzed by investigating the desorption solutions. According to the results of EEMs, protein/protein-like substances and SMP-like substances were the main components of the organic foulants, while the contribution of humic substances to the foulants was very limited, which is consistent with the results of HPSEC and ATR-FTIR.

(4) SMP-like substances in fouling layer increased with the filtration time, which were highly attributed to the transition from proteins to SMP according to the FRI method. Thus, the increase of SMP in the combined fouling layer would play a significant role on the accumulation of irreversible fouling.

\section{Acknowledgements}

This research was supported by grants from the National Natural Science Foundation of China (Nos. 51025830, 51008293 and 50908244). Thanks for the proof reading by the Dr. Yang S.F. from Nanyang Technology University. The technical assistances of Dr. Pan W. from Peking University and Mr. Shi K. from Applied Superconducting Research Center are highly appreciated.

\section{Appendix A. Supplementary data}

Supplementary data associated with this article can be found, in the online version, at http://dx.doi.org/10.1016/j.seppur.2012. 04.028 .

\section{References}

[1] J.G. Jacangelo, R. Trussell, M. Watson, Role of membrane technology in drinking water treatment in the United States, Desalination 113 (1997) 119-127.

[2] M.R. Wiesner, S. Chellam, Peer reviewed: the promise of membrane technology, Environ. Sci. Technol. 33 (1999) 360A-366A.

[3] X.Y. Li, H.P. Chu, Membrane bioreactor for the drinking water treatment of polluted surface water supplies, Water Res. 37 (2003) 4781-4791.
[4] H. Huang, K. Schwab, J.G. Jacangelo, Pretreatment for low pressure membrane in water treatment: a review, Environ. Sci. Technol. 43 (2009) 30113019.

[5] K. Kimura, N. Yamato, H. Yamamura, Y. Watanabe, Membrane fouling in pilot-1 scale membrane bioreactors (MBRs) treatment municipal wastewater Environ. Sci. Technol. 39 (2005) 6293-6299.

[6] F.G. Meng, F.L. Yang, B.Q. Shi, H.M. Zhang, A comprehensive study on membrane fouling in submerged membrane bioreactors operated under different aeration intensities, Sep. Purif. Technol. 59 (2008) 91-100.

[7] A.I. Schafer, A.G. Fane, T.D. Waite, Fouling effects on rejection in the membrane filtration of natural waters, Desalination 131 (2000) 215-224.

[8] N. Maximous, G. Nakhla, W. Wan, Comparative assessment of hydrophobic and hydrophilic membrane fouling in wastewater applications, J. Membr. Sci. 339 (2009) 93-99.

[9] H. Huang, N. Lee, T. Young, A. Gary, J.C. Lozier, J.G. Jacangelo, Natural organic matter fouling of low-pressure hollow-fiber membranes: effects of NOM source and hydrodynamic conditions, Water Res. 41 (2007) 3823-3832.

[10] V. Peter-Varbanet, J. Margot, J. Traber, W. Pronk, Mechanism of membrane fouling during ultra-low pressure ultrafiltration, J. Membr. Sci. 377 (2011) 4253.

[11] D. Jermann, W. Pronk, M. Boller, Mutual influences between natural organic matter and inorganic particles and their combined effection ultrafiltration membrane fouling, Environ. Sci. Technol. 42 (2008) 9129-9136.

[12] H. Yamamura, K. Kimura, Y. Watanabe, Mechanism involved in the evolution of physically irreversible fouling in microfiltration and ultrafiltration membranes used for drinking water treatment, Environ. Sci. Technol. 41 (2007) 6789-6794.

[13] L.H. Fan, J. Harris, F.A. Roddick, Influence of the characteristics of natural organic matter on the fouling of microfiltration membranes, Water Res. 35 (2001) 4455-4463.

[14] N. Lee, G. Amy, J.P. Croue, Low-pressure membrane (MF/UF) fouling associated with allochthonous versus autochthonous natural organic matter, Water Res. 40 (2006) 2357-2368.

[15] K.Y. Choi, B.A. Dempsey, In-line coagulation with low-pressure membrane filtration, Water Res. 38 (2004) 4271-4281.

[16] B.Q. Zhao, D.S. Wang, T. Li, C.W.K. Chow, C.P. Huang, Influence of floc structure on coagulation-microfiltration performance. Effect of $\mathrm{Al}$ speciation characteristics of PACls, Sep. Purif. Technol. 72 (2010) 22-27.

[17] K.J. Howe, M.M. Clark, Fouling of microfiltration and ultrafitration membrane by natural waters, Environ. Sci. Technol. 36 (2002) 3571-3576.

[18] T. Tran, R. Gray, B. Naughton, Bolto, Polysilicato-iron for improved NOM removal and membrane performance, J. Membr. Sci. 280 (2006) 560571.

[19] A. Al-Amoudi, P. Williams, A.S. Al-Hobaib, R.W. Lovitt, Cleaning results of new and fouled nanofiltration membrane characterized by contact angle, updated DSPM, flux and salts rejection, Appl. Surf. Sci. 254 (2008) 3983-3992.

[20] V. Geka, K.M. Perssona, M. Wahlgren, B. Sivik, Contact angles of ultrafiltration membranes and their possible correlation to membrane performance, J. Membr. Sci. 72 (1992) 293-302.

[21] D. Daffonchio, J. Thaveesri, W. Verstraete, Contact angle measurement and cell hydrophobicity of granular sludge from upflow anaerobic sludge bed reactors, Appl. Environ. Microbiol. 61 (1995) 3676-3680.

[22] Q.S. Wei, C.H. Feng, D.S. Wang, B.Y. Shi, L.T. Zhang, Q. Wei, H.X. Tang, Seasonal variations of chemical and physical characteristics of dissolved organic matter and trihalomethane precursors in a reservoir: a case study, J. Hazard. Mater. 150 (2008) 257-264.

[23] J.A. Leenheer, Comprehensive approach to preparative isolation and fractionation of dissolved organic carbon from natural waters and wastewaters, Environ. Sci. Technol. 15 (1981) 578-587.

[24] D.S. Wang, L.N. Xing, J.K. Xie, W.K. Chow, Z.Z. Xu, Y.M. Zhao, M. Drikas, Application of advanced characterization techniques to assess DOM treatability of micro-polluted and un-polluted source waters in China, Chemosphere 81 (2010) 1939-1945.

[25] W. Chen, P. Weaterhoff, J.A. Leenheer, K. Booksh, Fluorescence excitationemission matrix regional integration to quantify spectra for dissolved organic matter, Environ. Sci. Technol. 37 (2003) 5701-5710.

[26] C. Jarusutthirak, G. Amy, Role of soluble microbial products (SMP) in membrane fouling and flux decline, Environ. Sci. Technol. 40 (2006) 9699743.

[27] J.Y. Tian, Z.L. Chen, Y.L. Yang, H. Liang, J. Nan, G.B. Li, Consecutive chemical cleaning of fouled PVC membrane using $\mathrm{NaOH}$ and ethanol during ultrafiltration of river water, Water Res. 44 (2010) 59-68.

[28] H.K. Shon, S. Vigneswaran, S.A. Snyder, Effluent organic matter (EfOM) in wastewater: constituents, effects, and treatment, Environ. Sci. Technol. 36 (2006) 327-374.

[29] S.H. Kim, S.Y. Moon, C.H. Yoon, S.K. Yim, J.W. Cho, Role of coagulation in membrane filtration of wastewater for reuse, Desalination 173 (2005) 301307.

[30] S. Adham, K.P. Chiu, G. Lehman, C. Mysore, J. Clouet, Optimization of Membrane Treatment for Direct and Clarified Water Filtration, first ed., American Water Works Association, USA, 2007.

[31] W.R. Bowen, J.I. Calvo, A. Hernandez, Steps of membrane blocking in flux decline during protein microfiltration, J. Membr. Sci. 101 (1995) 153-165.

[32] N. Lee, G. Amy, J.P. Croue, H. Buisson, Identification and understanding of fouling in low-pressure membrane (MF/UF) filtration by natural organic matter (NOM), Water Res. 3 (2004) 4511-4523. 
[33] A. Baker, Fluorescence excitation-emission matrix characterization of some sewage impacted rivers, Environ. Sci. Technol. 35 (2001) 948-953.

[34] N. Her, G. Amy, H.R. Park, M. Song, Characterizing algogenic organic matter (AOM) and evaluating associated NF membrane fouling, Water Res. 38 (2002) 1427-1438.

[35] J. Cho, G. Amy, J. Pellegrino, Y. Yoon, Characterization of clean and natural organic matter (NOM) fouled NF and UF membranes, and foulants characterization, Desalination 118 (2002) 101-108.
[36] K.J. Howe, K.P. Ishida, M.M. Clark, Use of ATR/FTIR spectrometry to study fouling of microfiltration membranes by natural waters, Desalination 147 (2002) 251-255.

[37] S. Peldszus, C. Halle, R.H. Peiris, M. Hamouda, X.H. Jin, R.L. Legge, H. Budman, C. Moresoil, P.M. Huck, Reversible and irreversible low-pressure membrane foulants in drinking water treatment: identification by principal component analysis of fluorescence EEM and mitigation by biofiltration pretreatment, Water Res. 45 (2010) 5161-5170. 